\title{
Analysis on Vegetable Logistics Cost under Perspective of Optimizing Supply China
}

\author{
Weiyu Zhong \\ Hunan International Business Vocational College, Changsha, 410021, China
}

Keywords: Comprehensive economic strength; Logistics period; Logistics cost; Optimize supply chain

\begin{abstract}
The logistics is a standard which reflects the market competitiveness and comprehensive economic strength of one country. As for developed countries, they have strong economic strength, quick speed of logistics, novel model, and high level of logistics. It can be said that the logistics is a point which can improve economic growth of one country. In China, the logistics is continuously optimizing its mode and improving its service quality for China's economic growth; in particular, the logistics of agricultural products is of great significance for China as a large agriculture country. Due to different logistics period and methods for different objects, the involved logistics cost and economic benefit remains to be further explored. In order to inject the vitality into market economy, it is required to optimize supply chain, reduce cost, and improve logistics efficiency.
\end{abstract}

\section{Introduction}

China is a large agriculture country, thus a good logistics of agricultural products can greatly promote China's economy. Due to universality and persistence of consumption of agricultural products, to develop the logistics market of agricultural products is also the demand of China's economic development. However, in the process of logistics of agricultural products, we shall fully consider the territoriality and season, which causes the conflict in production and consumption of agricultural products. Take the logistics of vegetables as an example: due to multiple transaction links, long market circulation, and multiple times of loading and unloading, it is hard to keep vegetables fresh, cheap and safe; besides, the vegetable peasants are dispersed, which is not convenient for collection of vegetables; however, it can't be denied that there is large demand of vegetable market. Therefore, how to optimize supply chain, construct cheap logistics, and ensure that the consumers can timely eat inexpensive and fresh vegetables is a problem which shall be urgently solved in logistics industry.

\section{Analysis on vegetable supply chain mode}

The supply chain refers to a chain-type service structure formed by upstream and downstream business locations in the process of transporting logistic products to final users. The vegetable supply chain is a chain-type structure with overall function, and it is integrated with business flow, information flow, and logistics passed in the process of circulating vegetables from place of production to final consumption place, as well as producers, wholesalers and retailers, and distributors. A reasonable logistics supply chain can improve operation efficiency, dredge logistic paths, customize nodes, and expand the amount of information. The information can be delivered to each node of logistics; through digging market information, it is able to occupy the first market chance. Therefore, it can be seen that the vegetable supply chain is a main development direction for reducing vegetable cost and avoiding logistics waste.

\section{Joint mode of supply chain}

The joint mode of supply chain can provide accurate and feasible information, reduce circulation links, and shorten circulation time. This mode can be used to master the agricultural products produced by farmers and market demand, thus it is able to ensure that the most correct goods can be delivered and the most correct demand position can be found within the shortest time. This kind of 
quick and accurate circulation can reduce blind production and stabilize supply-demand relation of the market.

The joint mode of supply chain has some features. Firstly, its advantage is that it can ensure no waste of circulation time, and reduce the expense of unnecessary links to realize tight cooperation. Secondly, its advantage is that it has high organizations to form economic scale and certain benefits. In the whole logistics process, the logistics paths and structure are valid, which can avoid unnecessary waste of transportation. Thirdly, its advantage is that the high-degree information technology can quickly form logistics measures and effectively guide flow of commodity. The consumption terminal of logistics uploads the demand information to logistics service center which then timely feeds the information back to producers or suppliers. Therefore, this mode is accurate, timely, efficient, and resource-saving without need for inventory.

\section{Spontaneous mode of supply chain}

There is desire for batch transaction of agricultural products under the condition of economic development, and the agricultural development also urgently seeks for professional management organization. In various kinds of methods about solving the production and circulation, the spontaneous mode of supply chain gradually becomes mature. This mode is established under the condition that the farmers spontaneously contact each other; however, due to inaccurate information of market demand, multiple transportation links, high expense, and conflict between traders, this mode has many shortcomings. Due to instable transaction and blind production, this mode shows a trend of dispersed operation, random transaction, and small-scale wholesaling, and the economic scale can't be formed. This mode is suitable for small-scale producers; there are special traffickers between small-scale producers and consumers, and the large-scale economic transaction is not formed. Although the logistics is also required in the transportation process, the corresponding handling shall be made on vegetables in the links of classification, packaging, cold storage, loading and unloading, and keeping fresh; among those links, the links with the strongest logistic feature are packaging, loading and unloading, and classification of vegetables. It can be said that the features of logistics in this mode are obscure and reserved, which means that the functions of logistics are not fully exerted and the logistics can't provide comprehensive service in the process of vegetable circulation.

This mode also has its own features. Firstly, this mode is not systematic, not centralized, and fuzzy with weak information. This kind of information from spontaneous mode originates from place-of-origin brokers whose logistics concept is not mature, thus they carry out procurement, circulation, and information delivery by themselves at a slow speed and show a lagging state. Secondly, the picking-up, sales, and packaging of vegetables by farmers themselves waste time, energy, and money, the grade of organization is low, the peasants are distributed in a dispersed way, the petty dealers' operation is unstable, the failure rate of transaction is high, and it is not the conflict between supply and demand, but no meeting between them. Therefore, it can be seen that this mode remains to be further enhanced and changed.

Through judgment and analysis on above two modes, it can be confirmed that the information is an important element which can activate the supply chain. The driving force of information on supply chain can't be estimated; in case of strong information, the supply chain is active and perfect; on the contrary, in case of weak information, the supply chain is rigid. Therefore, it can be also confirmed that the vitality of logistics originates from information, and the logistics purpose and plan can have strong functions only when there is true and reliable information source.

\section{Cost analysis on vegetable supply chain}

Except for the important elements of common commodity supply chain such as management cost, transportation cost, and storage cost, the vegetable supply chain cost also has the elements with its own features. Because the circulation of vegetables requires short time, the loss will increase with the time extension. Therefore, the loss cost shall be also considered in the cost analysis on vegetable 
supply chain. According to the links of supply, circulation, and transaction of vegetables, we can define the vegetable supply chain cost as operation cost, transaction cost, and loss cost.

\section{Analysis on proportion of operation cost in vegetable supply chain cost}

The micro-logistics cost and macro-logistics cost are called logistics cost. The cost in micro significance refers to the cost between single enterprise and single enterprise, and the cost in macro significance refers to the cost of large-scale logistics operation. In the calculation process, the operation cost directly influences logistics cost, that is to say, the operation cost accounts for a large proportion in logistics cost. In foreign countries, Japan defines the content of logistics cost as packaging, loading and unloading, storage, transportation, processing, and delivery. Different from division of foreign operation cost, the domestic operation cost covers transportation cost, loading and unloading cost, storage cost, processing cost, packaging cost, information cost, and inspection cost. The specific content of those costs is defined as below:

From literal meaning, the transportation cost can be defined as the expense incurred in the circulation process of products. While the transportation cost is calculated, it is able to include employees' wage cost, vehicle loss cost, oil consumption cost, and road toll, all of which can't be ignored and they are called transportation cost together with fixed cost. The loading and unloading cost can be also easily understood, and it refers to the expense incurred in entering and exiting from warehouse, loading and unloading products from vehicles, and small-distance moving of products. Those procedures are necessary activities of logistics, and the possibility and times of some removal are uncertain, thus the loading and unloading cost is also a cost which accounts for a large proportion in operation cost. The storage cost refers to the expense incurred in storage time of products from starting point to ending point.

While the products arrive at medium-level consumption place, they shall be stored and kept before consumption, which will give rise to the expenditure. While we calculate the storage cost, we shall also consider depreciation of equipment and site leasing cost, both of which are also a part of storage cost. The processing cost refers to the cost of labor or mechanical expenditure incurred upon classifying the products, and such kind of cost calculation includes direct and indirect form. In general, the direct cost includes the cost of labor and mechanical expenditure incurred in products classification, as well as depreciation of equipment and mechanical maintenance, and the indirect cost includes management fee and business fee; the so-called management refers to the management of classification department and business expense while the products are delivered. The packaging cost refers to the expenditure incurred in coarse packaging in transportation process and refined packaging before sales. The sum of cost of labor, depreciation of equipment, and materials is packaging expense; the information cost refers to the expenditure incurred in processing logistics-related information. In the calculation process, the cost can be divided into three parts. The $1^{\text {st }}$ part is storage management information expense, including the processing of storage, remaining, removal, and classification information. The $2^{\text {nd }}$ part is ordering information expense, and it includes the sum of goods ordering, receiving, and delivering expense. The $3^{\text {rd }}$ part is customer service information expense. While the customers track and inquire goods, some payment is made, including the sum of personnel wage, depreciation of information equipment, and order processing expense. The inspection cost refers to the expenditure incurred while the quality of vegetables is checked in the circulation process, including personnel wage and depreciation of equipments.

\section{Analysis on proportion of transaction cost in vegetable supply chain cost}

The cost incurred while the transaction is made between producer and customer, and between customer and customer is the transaction cost. The so-called transaction cost in vegetable supply chain happens under the premise of transaction. Therefore, the research result of transaction cost can be summarized as: contract signing cost which includes agency fee and negotiating contract terms; cost incurred while the suppliers seek for intermediary and advertisement before transaction; cost which consists of contract fee and dispute cost after transaction.

As a kind of physical product, the vegetable also has its own features, and the transaction cost is also complicated; systematically speaking, the transaction cost also includes the cost incurred in negotiating, signing a contract, and acquiring information. Furthermore, the sales of vegetables is a 
long process in which the personnel, site, and other procedures all need cost. Therefore, it can be said that the transaction cost accounts for a big proportion in vegetable supply chain, which is only second to the operation cost.

\section{Analysis on proportion of loss cost in vegetable supply chain cost}

Just as the name implies, the loss cost refers to the cost paid due to damage of commodity in the physical process. In the circulation process, all commodities may more or less suffer damage, which is especially obvious in vegetables and fruits among those commodities. In terms of vegetable logistics, the long circulation time will directly influence the quality of vegetables, and also directly influence benefits. It can be said that the loss cost of vegetables is in direct proportion to their circulation time. What's more, while a certain time is up, the vegetables will be directly transited into waste products, and the loss is very direct. Therefore, in the vegetable supply chain, it is required to control the loading and unloading times of vegetables, the temperature of storage environment, the humidity required in circulation, and other factors to avoid more loss cost. Through comprehensive consideration on various kinds of factors causing the loss, the time is the factor with the biggest destructive power. From the picking of vegetables, and even from the growth of vegetables, the vegetables have started their transition from one end to another end. In the life cycle, if we can't properly handle those vegetable commodities, it means that purchasers will bear great economic loss.

The above content involves several cost contents and influence factors in vegetable supply chain, for it is just those factors that influence the circulation and cost of the vegetables. Through analysis on advantages and disadvantages of those factors, it is able to optimize the supply chain and then provide better service for vegetable logistics.

\section{Conclusion}

It can be seen that we shall not only consider the structural composition of supply chain, but also consider the logistics cost of vegetables in the analysis on logistics cost of vegetables under perspective of supply chain, and the most important thing is that we can't ignore the features reflected by vegetables in the logistics process and the concern problems. We shall combine with the current situation of market demand and circulation, optimize vegetable supply chain, improve vegetable logistics mode, fight a tough fight, seize the business opportunity and carry out accurate positioning to obtain bigger economic benefit of vegetables. The biggest feature of this paper is that this paper regards cost analysis of vegetables as key point, makes use of hypothesis of relevant links in supply chain to boldly integrate and optimize supply chain mode, constructs information exchange platform from perspective of supply and marketing, makes use of joint mode to expand vegetable logistics market and form transaction scale to build China as the first vegetable logistics center.

\section{References}

[1] Xie Zhihong, Hu Lijia. Cause Analysis on Drastic Fluctuation of Vegetable Price and Countermeasure Research under Perspective of Supply China, Journal of Anhui Agricultural Science, 2012 (36).

[2] Yu Jia. Analysis on Logistics Cost Management Based on Perspective of Supply Chain, Logistics Engineering and Management, 2012 (12).

[3] Yang Xiaolin. Relevant Problems of Rural Vegetable Logistics in China and Countermeasures, Journal of Southeast Guizhou Vocational College of Technology for Nationalities(Comprehensive Edition), 2010 (02).

[4] Fan Junhua, Chen Sumin. Discussion on Information-based Development of Vegetable Logistics under Regional Economy, Commercial Times, 2012 (04).

[5] Jin Jiang. Research on Operation Mode and Management of Fresh Vegetable Logistics in Hubei Province, Hubei. Wuhan University of Science and Technology, 2012. 